\title{
To Shed Some Light on Empowerment: Towards Designing for Embodied Functionality
}

\author{
Jelle van Dijk ${ }^{\mathrm{a}^{*}}$, Fenne Verhoeven ${ }^{\mathrm{b}}$ \\ a Twente University, the Netherlands \\ ${ }^{\mathrm{b}}$ Utrecht University of Applied Sciences, the Netherlands \\ *Corresponding author email: jelle.vandijk@utwente.nl
}

\begin{abstract}
We present a case study as part of an investigation into the value of Embodied theory for the design of mixed physical-digital interactive products. An interactive light system was designed that empowers an independent living person with an Autistic Spectrum Disorder (ASD) in managing domestic activities. Reflecting on the case we develop our vision of Embodied Functionality (EF). Designing for EF goes beyond 'distributing' information technology in the environment. It aims at creating interactive physical-digital products that play a functional role (i.e. become part of) a person's embodied being-in-the-world, involving a person's identity. It does so by utilizing existing structure and by supporting action-perception couplings, reflection in- and on action and autonomy in social coordination. EF opens up an alternative design space holding the promise of a more successful appropriation of interactive (assistive) products into people's everyday lives.
\end{abstract}

Keywords: Embodiment, Empowerment, Interaction Design, Situated Practice

\section{Introduction}

In this paper we explore the possible functional roles of interactive products within people's embodied practices by reflecting on a case of designing an assistive device for a person with Autistic Spectrum Disorder (ASD). The study is part of an ongoing investigation into the value of Embodied theory for designing interactive, mixed physical-digital systems (Van Dijk \& Van der Lugt 2013; Van Dijk et al, 2013; Van Dijk et al, 2014; Van Dijk \& Mitchell, 2014; Van Dijk \& Hummels, 2015; Hummels \& Van Dijk, 2015). 'Embodied theory' we use here as an umbrella term for a variety of notions that all share a basic commitment to the idea that the human body is essential to understanding the way people make sense of- and are able to act in- the world. It takes as a starting point the subtle interplay between brain, body and world (Clark, 1997), emphasizing how people are always already 'caught up' in the world as active, 
embodied beings. Consequently, people make sense of the world through skilful, situated interactions (Dreyfus, 2002). In our work we draw from phenomenology (Merleau-Ponty, 1962; Heidegger, 2013; Dreyfus, 1990) Situated Cognition (Suchman, 2007; Clancey, 1997; Lave, 1988; Rogoff \& Lave, 1984; Goodwin, 2000), Embodied- and Distributed Cognition (Clark, 1997; Hutchins, 1995; Kirsh, 2010) and theories on action-perception coupling and skill (Dreyfus, 2000; Ryle, 1949; Gibson, 1979, cf. Van Dijk et al, 2014, for an overview). Our interest is in finding out how mixed physical-digital products and systems may actively contribute to, i.e. become part of, a person's embodied being-in-the-world (Van Dijk \& Mitchell, 2014).

\section{Embodiment beyond distributed cognition}

One line of thought within Embodied theory that is popular with interaction designers is distributed cognition (Van Dijk, et al, 2014; Clark, 1997; Hutchins, 1995). Much of this work centres on reducing cognitive load in problem solving, by using physical objects to externally represent problems and compute solutions (Kirsh, 2010; Clark, 1997; Norman, 2002). Related theories call specific attention to the role of the social context, explaining how people collaboratively make sense of things, using concrete artefacts as binding elements (Bentley et al, 1992; Dourish, 2001; Luff et al, 2013). Hollan et al (2000) summarize: "[c]ognitive processes may be distributed across the members of a social group [and c]ognitive processes may involve ... external (material or environmental) structure." (Hollan et al, 2000, p. 176). Principles of distributed cognition are at play in a variety of new interface forms 'beyond the desktop', such as: tangible interaction (Ishii, 2008), multi-touch platforms (Fischer et al, 2000) and ubiquitous computing (Weiser, 1991; Abowd and Mynatt, 2000).

We have suggested elsewhere (Van Dijk et al, 2013; Van Dijk et al, 2014) that this line of work represents a quite modest application of Embodied theory to interaction design. Taking a phenomenology-inspired view, designing products that fully acknowledge and support our embodied being-in-the-world would suggest something more than distributing digital information into the physical- and social environment (See also Hummels \& Levy, 2013; Djajadiningrat et al, 2004; Robertson, 2002; Svanæs, 2013). Perhaps the question of how to design an interface to an information device already leads us astray, as it interprets the challenge as how to design an 'embodied interface' to pre-existing digital functionalities, instead of asking how the function of the device can be part of our 'embodiment' as such. Perhaps, then, we should ask how to design an interactive product (both physical form and interactive behaviour, which may include digital information processing) that becomes, in its totality, a meaningful element in a person's embodied practice. Theoretically, this means moving away from the focus on how to represent information. In its place we a potential design space opens up that highlights such aspects as the situatedness of human practices (Suchman; 2007; Lave, 1988; Dourish, 2001), action-perception couplings (Stienstra et al, 2011) and learning-by-doing (Klemmer et al, 2006; Schön, 1983). Our aim is precisely this: to design interactive artefacts that support people, as embodied copers (Dreyfus, 1990) in 
developing a grip on the world through their on-going, skilful interactions with it (Klemmer et al, 2006; Van Dijk and Mitchell, 2014).

In what follows, we further elaborate these themes using a case of designing an assistive device for a person with ASD. We reflect on the way in which concrete decisions in the design relate to the possible functional role of the system within this person's everyday practices. We first present our case study and its final design, an interactive light system supporting self-management of daily structure. We then present key design issues and observations that surfaced over the course of three iterations. For each issue we describe how it scaffolded our theoretical reflection, which in turn gradually sharpened our insights regarding the overall aim as mentioned above. We draw partial insights together in a discussion section in which we introduce the concept of Embodied Functionality (EF). The promise is that this concept may open up an alternative design space that goes beyond distributed information processing, incorporating a stronger concept of embodiment. Concerning the design of assistive technologies for people with special needs (Gitlin, 1995; Carmien et al, 2008; Ojasalo, 2010) we speculate that the concept of EF may help to create products that are less likely to be abandoned in practice (Philips and Zhao, 1993) and be incorporated by people supporting autonomy in everyday life. More generally we speculate that designs based on EF may contribute positively to the overall goal of a human-centred design, helping to ensure that products fit in well with the embodied practices of their users.

\section{Case study: interactive technological support for a person with autism}

In a participatory design project (Sanders \& Stappers, 2008) starting mid 2014, lasting one year, we designed for- and with one client, Max (not his real name, male, age 31, above average intelligence), with Asperger's syndrome (Bryson et al, 1997). We give a short impression of Max's situation before describing the design process. Max lives independently and by himself in fully equipped apartment in a supported living facility in a regular neighbourhood in a medium-sized city. His flat opens to an internal hallway where other clients with comparable needs are his neighbours. Max has a part-time job in a warehouse and he regularly cooks and eats with the people in his hallway in a central kitchen-living room. Max has three main professional caretakers (though the exact number varies), one of which is always available to the clients to offer assistance, occupying a control unit at the end of the hallway, during the day. His caretakers take turns in a daily 30-minute talk with Max about his daily affairs. Following recent developments in health-care policy, the organization that offers Max supported living services was interested in new technologies that could empower their inhabitants in living an independent life.

A known challenge for people like Max concerns executive functioning (Bryson et al, 1997), leading to impaired working memory and planning of tasks and inhibition of impulses. Compulsive and ritualistic behaviour may occur as well. As a result, mundane householdand administrative tasks become a challenge. External triggers easily distract Max. He is 
drawn towards 'irrelevant' details or caught by worries and fears, to the extent that the task as a whole is never finished. This may especially be challenging on a day off, when the structure of the day is less predictable and when Max is free to do what he wants, instead of receiving explicit work instructions. We decided to focus helping Max to remember, focus on and accomplish self-intended domestic activities (household, social, leisure, or otherwise).

Three main design iterations each resulted in a physical prototype and always included:

1) Refining the design challenge based on new insights

2) Exploring design opportunities building on previous iterations together with Max

3) Integrating ideas into viable concepts

4) Elaborating the most promising concept into an experienceable prototype

5) Evaluating prototypes with Max and caretakers in the actual context-of-use.

Interaction with Max included casual conversation, three longer interviews, collaborative acting out of Max's activities and collaborative reflection on various prototypes in his apartment, telephone conversation, email and chat. We also had interviews with two of the main caretakers, as well as with the manager of the facility, and with Max's nearest neighbour, also a person with Asperger's syndrome. The process moved progressively out of the studio into the actual use context (Hartswood et al, 2008). Once the second prototype was finished it remained at Max's home, to be picked up only when needed.

We took a Research-through-Design approach in the spirit of Overbeeke et al (2006). We use the iterative structure of a concrete design project to progressively weave together 1 ) ethnographical and collaborative insights into the user practice (Hartswood et al, 2008; Blomberg \& Karasti, 2012) 2) design insights concerning form and behaviour of the product, and 3) theoretical insight regarding Embodied theory (and its implications for design).

This means our understanding of Max's life, the design of the product and our understanding of the Embodied function of the artefact developed hand in hand, with each influencing the other along the way. Our approach is deliberately an in depth case for one client, investigating the historically and contextually developed details of an individual person's life-world (Agre \& Horswill, 1997; Brereton, 2013) and the potential supportive role of an interactive artefact in it. Our theoretical analysis however uses the case study insights to analyse the role of interactive products in embodied practices in a more general sense. (Hartswood et al, 2008; Blomberg \& Karasti, 2012).

\section{MYDAY}

In this section we describe the final design. MYDAY is a ubiquitous, interactive light system that helps clients like Max in structuring daily activities (Figure 1). Technically it consists of a set of wireless, multicolour light bulbs (Philips Hue; Figure 1.a) placed in conventional lampbodies, plus a central station we call the beacon (Figure 1.b, 1.c and 1.e). 
Figure 1.

MYDAY, an interac-

tive light system,

using the client's own

light sockets and a

central 'beacon', pro-

vides an augmented

layer of coloured light

over the existing

structure of objects

in the apartment.

Details in text.

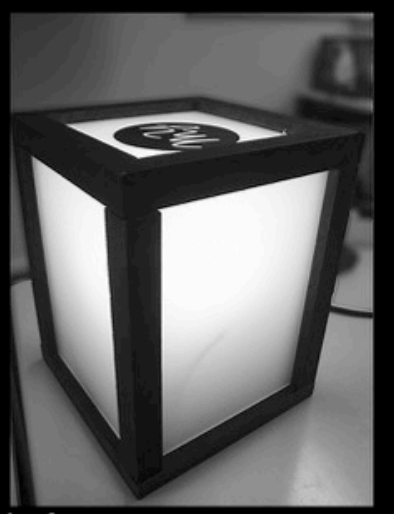

b) first prototype

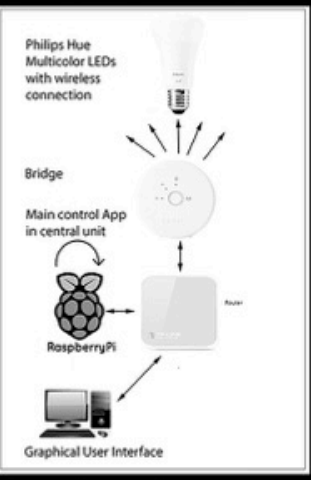

a) technical set-up

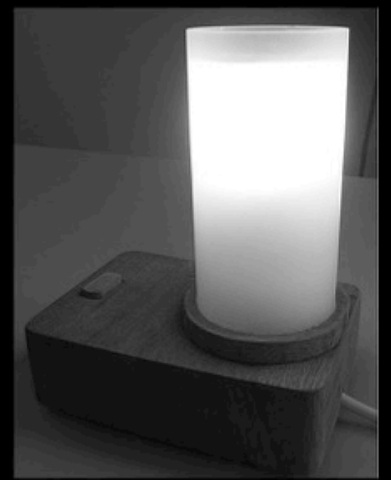

c) second prototype

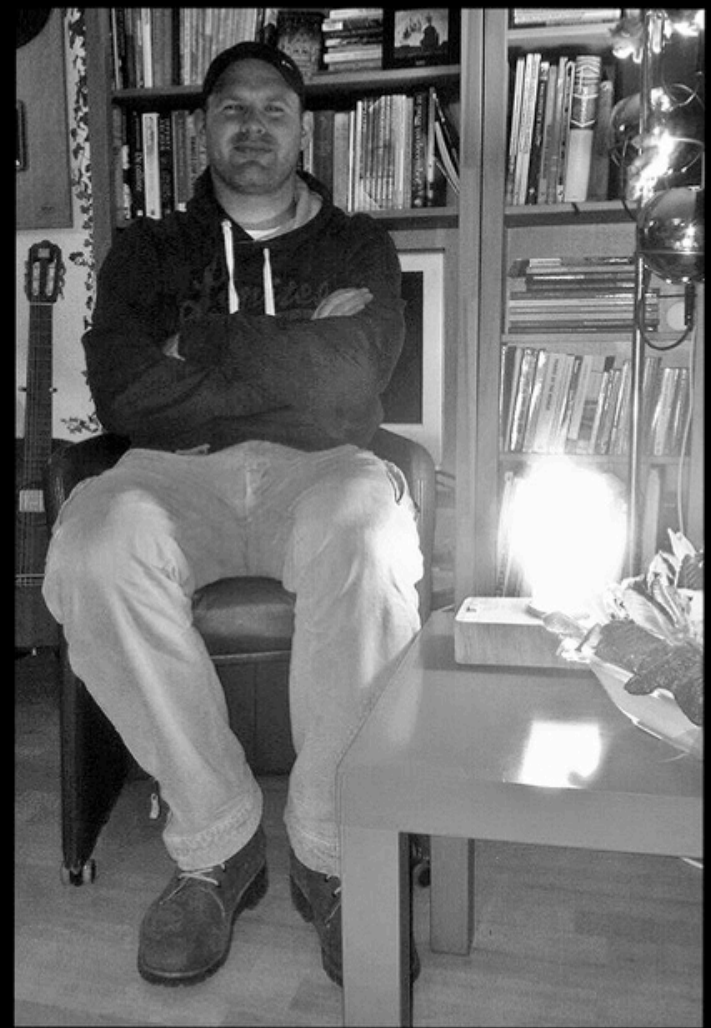

d) Max in his living room with second prototype

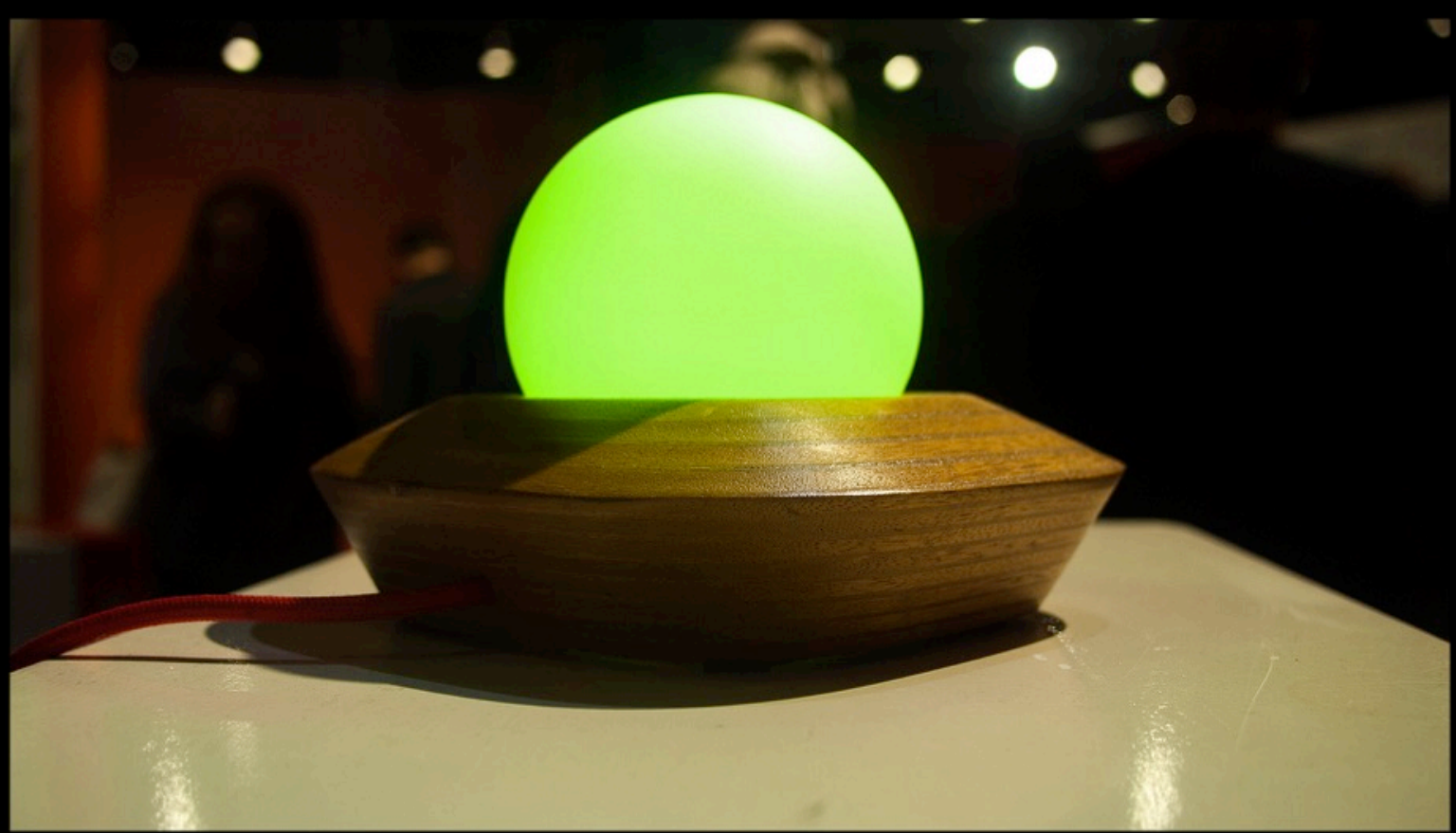

e) third prototype

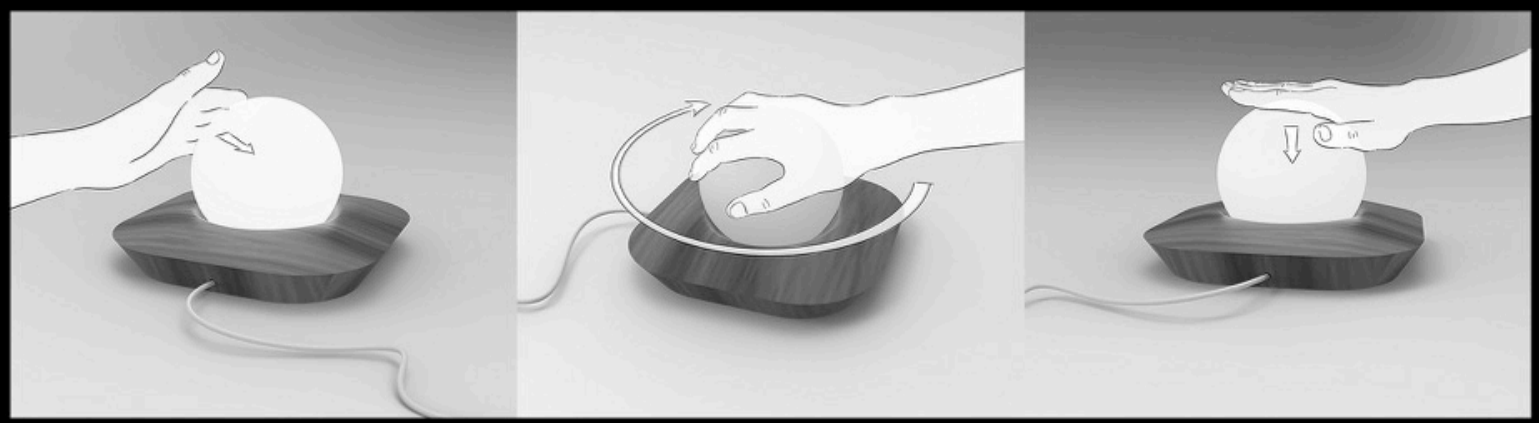

f) tangible interaction design: slapping the bowl skips a task, grinding the bowl in a circular motion deletes a task, and pressing the bowl for several seconds declares a task finished. 
Using MYDAY, Max plans a number of self-chosen activities, e.g. 'doing the dishes' or 'administration' via a conventional online calendar (Google) on his PC. Max assigns to each activity a time-window, a location in his apartment and a colour. The calendar communicates wirelessly with the beacon and light bulbs via an embedded Raspberry $\mathrm{Pi}$ server (Figure 1.a). When an activity is due, both the beacon and the lamp in the associated location light up in the selected colour, for the set time-window. This cues Max to start the associated task. Once the time is up, the next activity will 'light up' in the same way. Each activity thus has its own dedicated physical location, as seen fit in advance.

The second prototype (Figure 1.c) allowed three real-time user inputs on the beacon, by pressing a button once, twice or three times, in order to skip an activity, postpone an activity, or declare an activity finished. In the third prototype (Figure 1.e) we designed tangible interactions to replace the buttons (Figure 1.f).

\section{Insights from reflecting on the design case}

In this section we discuss five insights that grew out of concrete design considerations during the iterations, in relation to our growing understanding of Max's habits and routines, and relevant aspects of Embodied theory. These insights together build up to form our notion of Embodied Functionality, which we present in the discussion section that follows.

\section{Highlighting the existing action-affording structure in the environment}

Early on we explored with Max some ideas on sending reminders via a smart-watch. Max dismissed the smart-watch, saying it would distract him. He did not want 'yet another thing' to 'attend to', next to 'all the things he already needed to attend to'. He made a point of wanting to 'have his hands free'. We started thinking about a system that would completely blend in with Max's existing 'lifeworld' (Agre \& Horswill, 1997). We observed that his apartment contains many objects, in various arrangements, in boxes, bags, stacked on tables, cubboards, chairs, and on his ironingboard (Figure 2.). These familiar, 'habituated objects' (Brereton, 2013) are meaningfully coupled to Max's habits and routines. Yet given a specific task, the abundance of 'stuff' also creates distraction. People with ASD have difficulty attuning to larger wholes, and may be overwhelmed by large amounts of seemingly unrelated stimuli (Bryson et al, 1997). We observed Max initiating one activity, then half-way through being drawn to a certain object (a 'trigger', in the words of his caretaker), inviting Max to start a new activity, leaving the first unfinished. With interactive light, we decided to 'highlight' the relevant aspects of the apartment to the task at hand, while no extra effort would be needed of Max in order to interact with a separate system of reminders. MYDAY helps Max to focus on the relevant cues for action that the personal arrangements of things in his apartment already offer (Hutchins, 1995; Agre \& Horswill, 1997); a design concept quite unlike a tangible or wearable device offering 'reminders and notifications'. This was our first step towards developing the concept of 'embodied functionality'. 


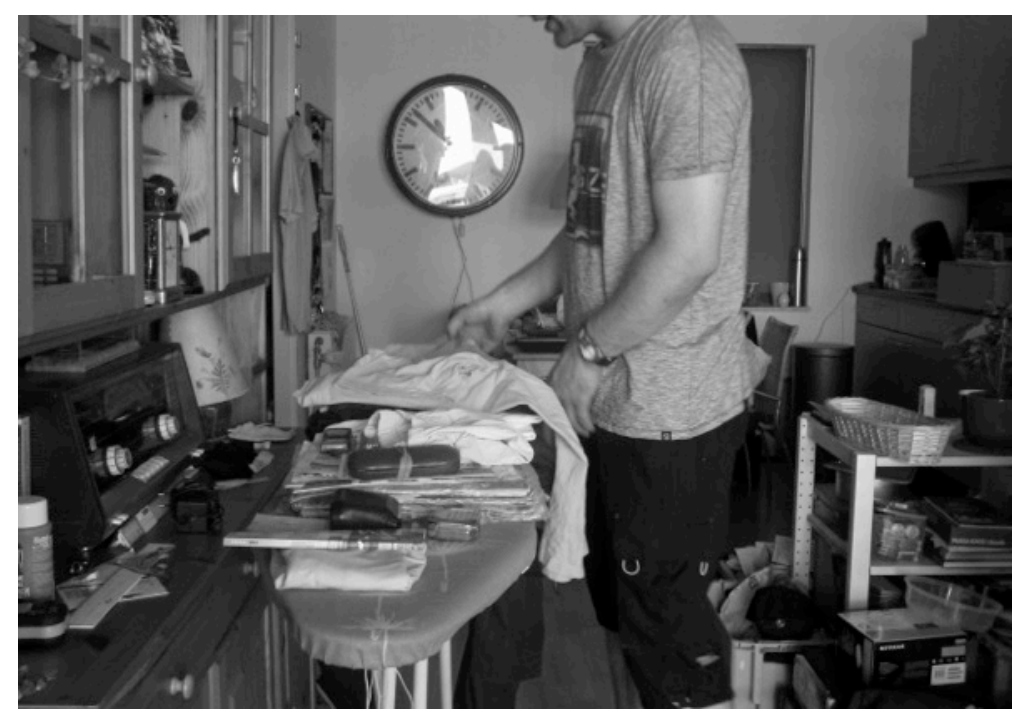

Figure 2: Max's lifeworld structure, with the ironingboard as an organizational platform.

\section{Supporting task-relevant action-perception couplings}

In trying to 'empower' clients in leading an independent life, many assistive systems have been proposed that provide the user with useful instructions on what to do (Gitlin, 1995; Carmien et al, 2008; Ojasalo, 2010). On the negative side, explicit instructions may actually make the receiver less empowered (Gitlin, 1995). In this regard, Max showed explicit aversion towards the planning schedules pinned on his corkboard (Figure 3). Max: 'I know they are useful, but it feels like they take away my freedom'. We wanted to retain Max's sense of freedom. We realized Max is actually not in need of instructions. He knows what he wants to do. His problem concerns staying on track while he is doing it. This is why the coloured light does not say what the task is, only that 'a task' should start 'about now', 'over there'. In Suchman's terms, MYDAY transforms the plans (in the calendar) into dynamic cues that invite situated actions (Suchman, 2007). It does not prescribe action: what Max does emerges from his interactions and is not derived from following instructions a system provides. The light taps into what Dreyfus calls 'absorbed coping' (Dreyfus, 1990) the largely unconscious mode of interaction driven by affordances in the environment (Gibson, 1979). It takes part in action-perception couplings (Van Dijk et al, 2014) by drawing visual attention to relevant elements in the environment, what Goodwin calls, interestingly, 'highlighting for perception' (Goodwin, 1994).

\section{Planning as reflection-on-action leading to adaptation of habits and space.} In MYDAY Max plans his activities using a calendar. As said, in embodied routines, plans are artefacts that reorient embodied actions, rather than prescribing them (Suchman, 2002):

"As projective and retrospective accounts of action, plans are themselves located in the larger context of some on-going practical activity. (Suchman, 2007, p. 69)" 
We realized that the activity of planning the calendar is not only an interface operation in order to put plans in the digital system. It is also an opportunity to reflect on past events, in Schön's sense of reflection-on-action (Schön, 1984, see also Van Dijk et al, 2011). In this light we envisioned a scenario in which planning the calendar would be part of the daily meeting of Max with his caretaker. Planning the next day is explicitly a moment of stepping back from the on-going flow of action, a moment to look at your own activities from a distance. With some help of the caretaker, the new lighting plan incorporates 'lessons learned' from before.

Planning activities with MYDAY may not only change Max's understanding of his own behaviour, it may also literally change the physical organisation of the space. Presently, Max's room is cluttered with objects. As Max keeps being distracted in the midst of an activity, abandonment his projects produces an even more disorderly configuration of stuff which results in even more distracting triggers, creating a dysfunctional feedback loop in which chaos creates more chaos. His caretakers often instruct him to tidy up and put everything 'in its proper place', but Max feels this as belittling, and even if he accepts it in theory, it is hard to stick to in practice. The idea of MYDAY is to allocate activities to locations. This means Max is prompted to think about what tasks should go 'where', close to one of his lamps. Our idea is will lead him to gradually reorganize objects and lamps so as to make more effective use of the system. When the project was halfway through, Max indeed started to talk about his apartment in terms of sections divided by the lamps:

"On this side of the room" \{makes a cut with his hand in the air, then points to the window\} "is where I have talks with my caretaker \{pause\} by that lamp \{points to a lamp at the window\}, while on this side \{gestures towards kitchen table\} is where I fold my laundry, under this lamp \{points at the table lamp\}"

This suggests, we speculate, that Max started to reconfigure his own perception of the space in terms of spatially organized workspaces, each reserved for certain tasks, a characteristic of properly functioning lifeworlds (Agre and Horswill, 1997). That is, in using the system, Max's space may become gradually transformed into more effective configurations, without the feeling of being forced to give up on "ones' own preferred ways of doing" (Gitlin, 1995).

\section{Tangible interaction affording reflection-in-action}

Once we saw the 'offline' planning activity as an instance of reflection on action, we explored possibilities of reflection 'in action' (Schön, 1983). This we kept in mind when designing a set of tangible interactions on the beacon. By pressing the bowl, Max is prompted to take a moment to acknowledge the fact that indeed he has successfully finished a task: something to celebrate. Likewise, the 'grinding motion' to delete a task makes Max is conscious of taking responsibility for the consequences of deciding not to do something he had planned. The interaction thus invites reflection-in-action, what we called a 'micro-moment of reflection' (Van Dijk et al, 2011). Note that tangible interaction design is used here not as providing an 'intuitive' or 'easy' interface to digital information. The tangible interactions of prototype 3 have little information value over and above the basic button in prototype 2 (Figure 1.c). Instead, we used tangible forms to invite the embodied 
action that goes along with reflection-in-action, which is needed for developing a skill in dealing with comparable situations (Klemmer et al, 2006; Dreyfus, 2002).

\section{Supporting autonomy in social coordination}

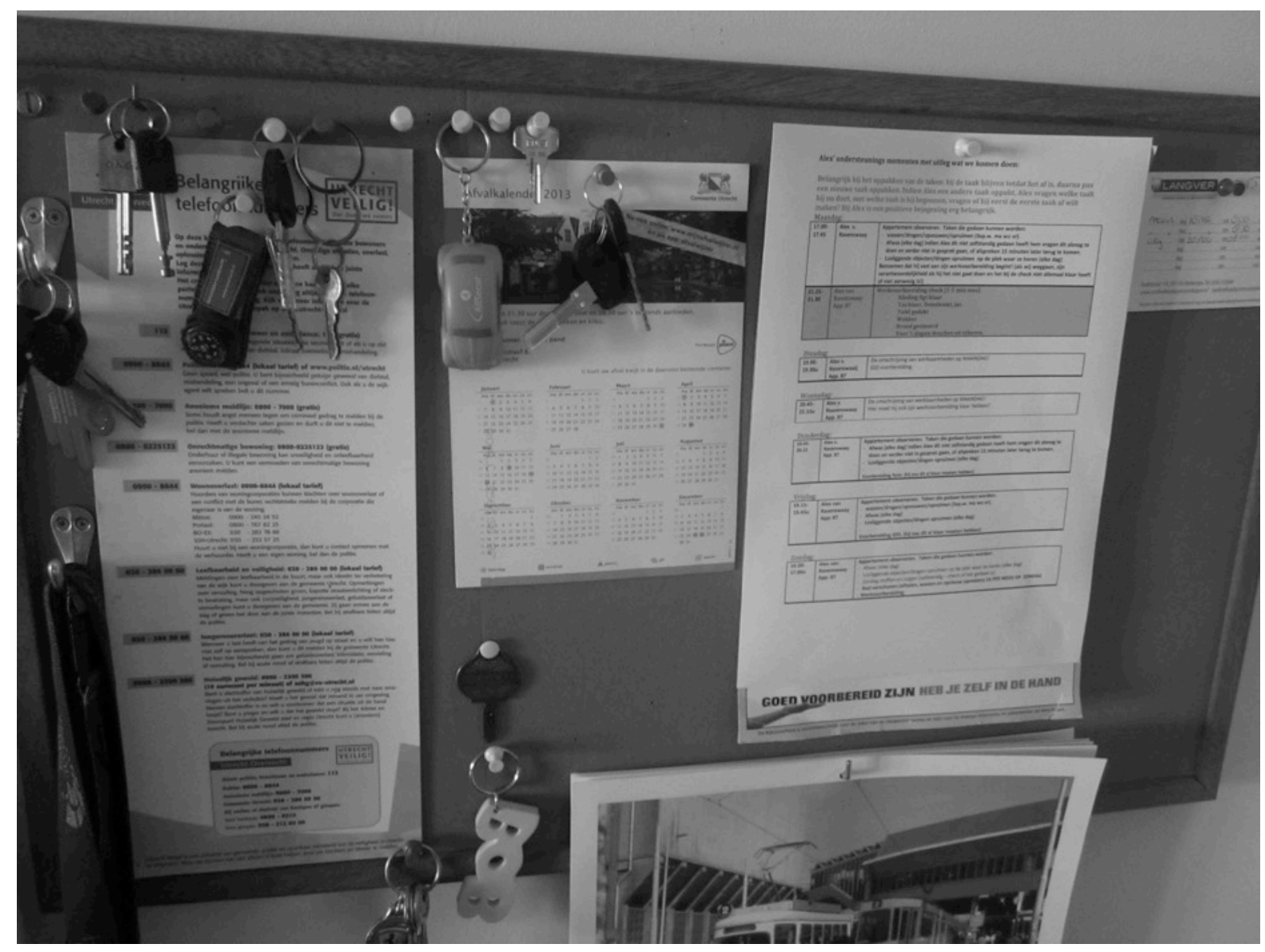

Figure 3. Planning schedule created and pinned to the corkboard by the caretaker (right side).

Situated Cognition explains how artefacts mediate social relations (Brereton, 2013, Lave, 1988; Suchman, 2007). During the project we came to see how MYDAY mediated Max's sense of autonomy in relation to his caretakers. MYDAY supports Max to live life his own way, rather than technology imposing on him externally defined methods. The lamp highlights his configuration of objects in the space, configurations that are meaningful to Max. Max programs the lamp. He puts his plans into the system. The cues are essentially 'notes to self', not instructions by his caretakers. During the project, 'the lamp' helped Max him take a (more) autonomous role in negotiations with his caretakers. For example, at some point Max began to explicitly contrast 'his lamp' (see Figure 1.d) with the planning schedule mentioned earlier (Figure 3.) Max told us on various occasions how one caretaker had heard about the 'lamp project', expressed her enthusiasm, and promptly proposed to 'put all the tasks of the schedule into the lamp'. For Max, this was out of the question: "I said to her, wait a minute, not so fast, we are not going to put your schedule into my lamp". This illustrates how artefacts not only contain information but also mediate social (power) 
relations (Suchman, 2007). Later on he added that perhaps it would be good to put the schedule into the lamp, because he knew it 'was good for him', yet he continued to have issues with the idea. We concluded these social micropolitics should actually be an explicit function of the device. Programming the lamps could be one of the returning topics in the daily meeting with the caretaker. By focusing together on the practical question of how to 'program the lamps for the next day', a clash of opposing views might be avoided. The resulting configuration would be a compromise between Max and his caretaker. The lamps are not representative of one party (as the schedule was the caretaker's view on what's best for Max). Taken together, the lamps function to support participatory sensemaking involving Max and his caretaker (De Jaegher and Di Paolo, 2007; Van Dijk \& Hummels, 2015; Hummels \& Van Dijk, 2015).

\section{Towards Embodied Functionality}

We started out suggesting that designing for embodiment means more than designing for distributed cognition by means of tangible or wearable technologies (Van Dijk, et al, 2014). In this section we draw our insights together to discuss what this 'more' means, concretely.

\section{Designing for Embodied Functionality}

Phenomenological, action-oriented theories of embodiment (Merleau-Ponty, 1962, Dreyfus, 2002, Noe, 2004) first and foremost ask the question of how people live their world, rather than how they represent it. The starting observation is that people are always already dealing with the world, and how, in the course of that dealing, certain aspects of the world show up as meaningful. Ongoing parallel flows of perception and action lead to couplings that we may call embodied skills (Ryle, 1949; Dreyfus, 2002). Through such skilful coupling we attain 'grip' on the world (Merleau-Ponty, 1962). This is why we perceive the world first and foremost in terms of affordances for action (Gibson, 1979). Of interest to us in particular is the fact that artefacts are readily appropriated and taken up within such couplings, up to the extent that they can be seen as extensions of ourselves. In this regard, the phenomenologist Merleau-Ponty writes:

"Sometimes, finally, the meaning aimed at cannot be achieved by the body's natural means; it must then build itself an instrument, and it projects thereby around itself a cultural world" (Merleau-Ponty, 1962, p. 169).

The 'cultural' referred to by Merleau-Ponty hints at another aspect of our embodiment. What ethnomethodology has understood quite well is that action-perception couplings emerge as always already situated in a practice, and practices are a social affair (Rogoff \& Lave, 1984; Suchman; 2007). This entails that getting a grip on the world is a participatory achievement (De Jaegher \& Di Paolo, 2007), something we do against a socially situated background, mediated by artefacts.

In all, the world we live, our lifeworld, which includes our designed tools and artefacts, is not the physical space surrounding our physical body, but rather what is called the enacted 
world (Varela et al, 2001) that we skilfully and socially sustain. Agre \& Horswill (1997), drawing on Schutz (1967), define the lifeworld as "an environment described in terms of the customary ways of structuring the activities that take place within it ... maintained by conventional uses of tools and materials " (Agre \& Horswil, 1997, p. 118).

We sought to design interactive products that, both in function as well as in form, play a meaningful role in sustaining a person's embodied couplings to the lifeworld. The design of MYDAY illustrates a number of possibilities to do so:

- Highlighting relevant aspects of the action-affording structure in the environment

- Supporting task-relevant action-perception couplings

- Supporting learning through reflection in- as well as on action

- Supporting autonomy in social coordination

Together, these principles make up what we call designing for Embodied Functionality (EF).

$E F$ is meant to reframe and give new direction to design. Taking the field of assistive technologies as an illustration, we give two examples of where EF may be used to reframe orthodox conceptions of designers. First, we currently see a proliferation of devices that essentially provide contextualized instructions and notifications to the user. Take for example pill-dispensers that notify the user to take a medicine (Gitlin, 1995; Ojasalo, 2010). The question is whether all these notifications and reminders really help clients in the actual, practical circumstances of everyday life. Likewise, wearable- and ubiquitous systems are increasingly used to gather large amounts of behavioural data and continuously monitor the client (Seppälä et al, 2014). Monitoring is certainly useful for researchers and therapists, but it is less clear how these Big Data can be meaningful in supporting how a person lives his own life and how s/he may experience autonomy. We believe that the notion of Embodied Functionality may be used to critically examine such questions and explore alternative kinds of products that take on a different role than do the majority of assistive devices today.

\section{Further understanding of Embodied Functionality}

In closing we comment on how this particular case study provided us with a fresh perspective on Embodied theory itself, which sharpened our insights in several ways.

First, the case invited us to be more explicit about the role of learning, i.e. adapting ones' routines and habits through experience. Schön's famous concepts of reflection in- and on action (Schön, 1983) seem to work quite well to describe how a person may temporarily step back from his activity, reflect, and gradually develop both his skills and routines as well as reorganize the objects and tools in his lifeworld to better fit those skills and routines.

Second, the goal of designing for empowerment, central to this case, brought insight into the way embodied interaction through interactive artefacts relates to a person's sense of autonomy and self-control, something that we had not analysed clearly before. This relation is not new to Embodied theory. Dreyfus (1991), Clancey (1997) and Lave (1988) all have discussed the relation between embodied action and ones' sense of self. Heidegger analysed 
how the hammer as 'equipment' relates to the identity of the carpenter within a community of practice (Heidegger, 2013). In this regard it is interesting that Riemer and Johnston (2014) claim much of todays' IT technology actually lacks the quality of equipment:

\footnotetext{
"Use of equipment is at the heart of our human way of being, which is to be engaged in practices. Practices and equipment are constitutive of self ... [I]ndividuals express their (professional) identities through the equipment they use. Replacing this equipment [with information technology] might in the worst case equate to tearing apart one's (professional) lifeworld, one's existence, which was built on the basis of what one does and therefore how (in what way) one 'is'" (Riemer \& Johnston, 2014, p.10.)
}

That is, learning to, and being able to skilfully use equipment, as part of ones' being-in-theworld is a prerequisite for being an autonomous person. We believe EF may help to design interactive technologies that function as equipment - in other words, which help a person to be autonomous, and thereby, to be most fully himself. In the context of designing assistive technologies for people with special needs, such as Max in our case, we see empowerment as precisely as the degree to which one is able to "express [ones'] identity through the equipment [one] use[s]". Using the product should feel like 'something I do with the tool', rather than as 'something the tool does for me' or something 'the tool instructs me to do'.

\section{Conclusion and future work}

In a one-year participatory design process we explored how an embodied perspective would play out in designing a system for and with Max, an independently living person with ASD. By reflecting on the design and developing a growing insight into Max's lifeworld, we explored an alternative functional role of assistive technology in supporting embodied practices. We call this Embodied Functionality (EF), which means to guide a person towards the actionaffording structure of a person's own environment, to sustain action-perception couplings, to enable reflection in-and on action, and to strengthen a person's autonomy within social coordination. In the context of assistive technologies we speculate that designing for EF can create products that will be more readily accepted and appropriated in embodied practices, and thereby less likely to be abandoned (Philips and Zhao, 1993). Currently we are developing a robust working prototype of MYDAY that can function for several weeks without technical assistance, to assess more deeply the actual ways in which the system comes to function as an aspect of Max's everyday life. Furthermore, we intend to explore possibilities of incorporating movement sensing and action monitoring, with the aim of investigating in a critical way how, from an Embodied Functionality perspective, these technological trends may add real value to a person's empowerment.

Acknowledgements: Thanks to Max, to all students of Utrecht University of Applied Sciences and University of Twente that collaborated in this project, and to all those involved within Philadelphia Care Organization. 


\section{References}

Abowd, G. D., \& Mynatt, E. D. (2000). Charting past, present, and future research in ubiquitous computing. ACM Transactions on Computer-Human Interaction (TOCHI), 7(1), 29-58.

Agre, P. and Horswill, I. (1997). Lifeworld analysis. Journal of Artificial Intelligence Research, 6, 111145.

Arias,E., Eden, H., Fischer, G., Gorman, A., Scharff, E. (2000) Transcending the individual human mind-creating shared understanding through collaborative design. Trans. on Computer-Human Interaction 7 (1). 84-112

Bentley, R., Hughes, J.A., Randall, D., Rodden, T. Sawyer, P., Shapiro, D. and Sommerville, I. (1992): Ethnographically-Informed Systems Design for Air Traffic Control. In J. Turner and R. Kraut (eds.): Sharing Perspectives, Proc. Of CSCW'92. Toronto, Canada, ACM: New York, pp. 123-129.

Blomberg, J. and Karasti., H. (2012). Positioning ethnography within Participatory Design. London: Routledge.

Bradley, N.A. and Dunlop, M.D. (2005). Towards a Multidisciplinary Model of 'Context' to Support Context-Aware Computing. Journal of Human-Computer Interaction, 20. 403-446.

Brereton, B. (2013). Habituated objects: everyday tangibles that foster the independent living of an elderly woman. Interactions, 20(4). 20-24.

Bryson, S., Landry, R. and Wainwright, J.A. (1997). A componential view of executive dysfunction in autism: Review of recent evidence. In: Jacob A. Burack and James T. Enns, (Eds). Attention, development, and psychopathology, New York: Guilford, 232-259.

Clancey, W. J. (1997) Situated cognition : On human knowledge and computer representation. Cambridge, MA: Cambridge University Press.

Clark, A. (1997) Being there: Putting brain, body and world together again. Cambridge, MA: MIT Press.

De Jaegher, H. and Di Paolo, E. (2007) Participatory sense-making: An enactive approach to social cognition. Phenomenology and the Cognitive Sciences, 6(4), 485-507.

Djajadiningrat, T., S. Wensveen, J. Frens, and K. Overbeeke. (2004). Tangible products: redressing the balance between appearance and action. Pers Ubiquit Comp, 8, Springer-Verlag. pp. 294- 309, 2004.

Dourish, P., Where the action is: the foundations of embodied interaction: MIT Press. 233 pp. 2001.

Dreyfus., H.L. (1990). Being-in-the-world: A commentary on Heidegger's Being and Time, Division I. Cambridge (MA): MIT.

Dreyfus, H.L. (2002) Intelligence without representation: Merleau-Ponty's critique of mental representation. Phenomenology and the Cognitive Sciences, 1, 367-83

Carmien, S. P., \& Fischer, G. (2008). Design, adoption, and assessment of a socio-technical environment supporting independence for persons with cognitive disabilities. In Proc. of the SIGCHI Conference on Human Factors in Computing Systems (pp. 597-606). ACM.

Gibson, J.J. (1979) The Ecological Approach to Visual Perception, Houghton Mifflin, Boston.

Gitlin, L.N. (1995). Why older people accept or reject assistive technology. Generations 19(1). 41-46.

Goodwin, C. (2000). Action and embodiment within situated human interaction. Journal of pragmatics, 32, 1489-1522.

Goodwin, C. (1994), Professional vision. American Anthropologist, 96, 606-633. 
Hartswood, M., Procter, R., Slack, R., Voß, A., Büscher, M., Rouncefield, M., \& Rouchy, P. (2008). Corealization: Toward a principled synthesis of ethnomethodology and participatory design. Scandinavian Journal of Information Systems, 14(2), 9-30.

Heidegger, M. (2013). Zijn en Tijd. Nijmegen: Sun. [Dutch trans. M. Wildschut of: Heidegger, M. (1927). Sein und Zeit. Tübingen: Max Niemayer Verlag.]

Hutchins, E. (1995). Cognition in the Wild. Cambridge (MA): MIT press.

Hummels, C.C.M., \& Van Dijk, J. (2015) Seven Principles to Design for Embodied Sensemaking. Proceedings of TEl'15, pp. 21-28, Stanford. New York: ACM.

Hummels, C.C.M. \& Lévy, P.D. (2013). Matter of transformation : designing an alternative tomorrow inspired by phenomenology. Interactions, 20(6), 42-49.

Hollan, J., Hutchins, E. and Kirsh, D. (2000) Distributed Cognition: Toward a new Foundation for Human-Computer interaction research. ACM Transactions on Computer-Human Interaction, Vol. 7, No. 2, Pages 174-196.

Hiroshi Ishii. 2008. Tangible bits: beyond pixels. Proc TEI'08. ACM.

Klemmer, S.R., Hartman, B. and Takayama, L. (2006). How bodies matter: five themes for interaction design. In: DIS 2006, ACM Conference on designing interactive systems, (June 26-28, University Park, Pennsylvania, USA, pp. 140-149), New York: ACM.

Kirsh, D. (2010) Thinking with external representations. Al \& Society, 25, pp. 441-454.

Lave, J., (1988) Cognition in Practice. Mind, mathematics and culture in everyday life. Cambridge University Press.

Luff, P., Jirotka, M., Yamashita, N., Kuzoaka, H., Heath, C. and Eden, G., (2013). Embedded Interaction: The Accomplishment of Actions in Everyday and Video-Mediated Environments. ACM Trans. on Computer Human Interaction, 20(1).

Merleau-Ponty, M. (1962) Phenomenology of Perception. New York: Routledge \& K. Paul.

Noe, A. (2004) Action in perception. Cambridge: MIT Press.

Norman, D.A. (2002). The design of everyday things. New York: Basic Books

Overbeeke, C.J., Wensveen, S. and Hummels, C.C.M. (2006). Design Research: Generating Knowledge through Doing. In Swiss Design Network. Drawing New Territories. State of the Art and Perspectives. Third Symposium of Design Research, 17-18 Nov, Geneva. Geneva: Swiss Design Network.

Ojasalo., J. (2010). Better technologies and services for smart homes of disabled people: Empirical findings from an explorative study among intellectually disabled. Proc of ICSTE 2010, 1, V1-251-V1259.

Phillips, B. and Zhao, H. (1993). Predictors of assistive technology abandonment. Assistive Technology 5(1): 36-45.

Kai Riemer, and Robert B. Johnston. 2014. Rethinking the place of the artefact in IS using Heidegger's analysis of equipment. European Journal of Information Systems 23(3): 273-288.

Robertson, T. (2002) The public availability of actions and artefacts. Computer Supported Cooperative Work, 11: 299-316.

Rogoff, B. \& Lave, J. (1984). Everyday cognition: Its development in social context. Cambridge, MA: Harvard University Press.

Ryle, G. (1949). The concept of mind. New York: Barnes \&Noble.

Seppälä, A., Nykänen, P., \& Ruotsalainen, P. (2014). Privacy-Related Context Information for Ubiquitous Health. JMIR mHealth uHealth, 2(1). 
Schön, D.A., (1983). The reflective practitioner - how professionals think in action. New York: Basic Books.

Schutz, A. (1967). The phenomenology of the social world. Northwestern University Press.

Sanders, E. and Stappers, P-J. (2008). Co-creation and the new landscapes of design. Co-design 4(1): 5-18.

Stienstra, J.T., Overbeeke, C.J. \& Wensveen, S.A.G. (2011). Embodying complexity through movement sonification : case study on empowering the speed-skater. Proceedings of the 9th ACM SIGCHI Italian Chapter International Conference on Computer-Human Interaction, New York: ACM, 39-44.

Suchman, L.A. (2007) Human-Machine Reconfigurations: Plans and Situated Actions 2nd expanded edition. New York and Cambridge UK: Cambridge University Press.

Svanæs, Dag. (2013) Interaction Design for and with the Lived Body : Some Implications of MerleauPonty's Phenomenology. ACM Transactions on Computer-Human Interaction. vol. 20 (1).

Van Dijk, J. \& Hummels, C.C.M. (2015) Designing for Participatory Sensemaking. Proceedings of EAD'11, Paris.

Van Dijk, J., Van der Lugt, R., \& Hummels, C.C.M. (2014) Beyond Distributed Representation: Embodied Cognition Design Supporting Socio-Sensorimotor Couplings. Proceedings of TEl'14, pp. 181-188, München. New York: ACM.

Van Dijk, J. \& Mitchell, R. (2014) Co-Embodied Technology: A Design space for Human Being. Proceedings of TEl'14, Work-in-Progress, München. New York: ACM.

Van Dijk, J. and Van der Lugt, R. (2013) Scaffolds for shared understanding. AI EDAM, Special Issue on Design Communication, 27, 107-117.

Van Dijk, J., Moussette, C., Kuenen, S. \& Hummels, C.C.M. (2013) Radical clashes: what Tangible interaction is made of. Proceedings of TEl'13, pp. 323-326, Barcelona. New York: ACM.

Van Dijk, J. Roest, J. Van der, Lugt, R. \& Overbeeke, C.J. (2011) NOOT: A tool for sharing moments of reflection during creative meetings. C\&C'11, Atlanta, Georgia, USA. New York: ACM.

About the Authors:

Author 1 Jelle van Dijk is Assistant Professor at University of Twente. He uses participatory design and RtD to investigate the value of Embodied theory for designing interactive mixed physical-digital systems. His current interest is in designing for people with socialcognitive disabilities.

Author 2 Fenne Verhoeven is senior researcher at Utrecht University of Applied Sciences developing co-design methods and tools, especially for health-care. Her work involves children with cancer and children ASD and spans both the fuzzy front-end as well as the final evaluation phase. 